\title{
Editorial dossier "Sistemas procesales penales e imparcialidad del juez": Imparcialidad y prueba en el proceso penal - reflexiones sobre la iniciativa probatoria del juez
}

\author{
Editorial dossier "Criminal Procedure Systems and Judicial \\ Impartiality": Impartiality and evidence in criminal procedure - \\ consequences to judge's evidence power
}

Editorial dossiê "Sistemas processuais penais e imparcialidade judicial": Imparcialidade e prova no processo penal reflexos sobre a iniciativa probatória do juiz

Lorena Bachmaier Winter ${ }^{1}$

Universidad Complutense de Madrid/Espanha

1.bachmaier@der.ucm.es

https://orcid.org/0000-0002-9212-3336

\begin{abstract}
RESUMEN: El presente trabajo pretende clarificar cuál es la relación entre el principio de imparcialidad y la intervención del juez en la práctica de la prueba. En otras palabras, si reconocer al juez determinadas facultades en la práctica de la prueba atenta contra la garantía de la imparcialidad. Se planteará si la garantía de la imparcialidad requiere la absoluta pasividad del juez en el desarrollo del debate contradictorio o si, por el contrario, se trata de una exigencia derivada de una determinada concepción del modelo contradictorio. Las respuestas que demos a estas cuestiones incidirán directamente en la valoración de la posición del juez en relación con la práctica de la prueba, si la misma ha de excluirse o limitarse o, por el contrario, no afectando al
\end{abstract}

1 Professora Catedrática da Universidad Complutense de Madrid. Doutora em Direito pela Universidad Complutense de Madrid (Espanha) e doutora honoris causa pela Universidad San Pedro (Perú). 
principio de imparcialidad, es una cuestión relacionada con los fines del proceso. Para ello analizará previamente el concepto de imparcialidad y sus diversas acepciones.

Palabras clave: imparcialidad judicial; independencia; prueba; proceso penal; sistemas procesales; sistema acusatorio; modelo contradictorio; sistema adversarial.

ABSTRACT: The aim of this paper is to clarify the relationship between the principle of impartiality and the role of the judge in the trial with regard to the evidence. In particular I will argue that recognizing certain powers to the judge to intervene in the cross-examination of witnesses or interrogating the defendant, does not necessarily undermine the fundamental right to an impartial judge. It will be analyzed if the principle of impartiality does per se justify a completely passive role of the trial judge, or rather a position of the judge as mere spectator is a requirement of a certain understanding of the adversarial model. To this end, I will first address the concept of impartiality and its various meanings.

KEYWORDS: judicial impartiality; judicial independence; criminal procedure; models of procedure; adversarial system; accusatorial system; right to confrontation.

RESUMO: O objetivo deste trabalho é esclarecer a relação entre o princípio da imparcialidade e o papel do juiz no julgamento no que diz respeito à prova. Em outras palavras, se reconhecer algumas faculdades ao julgador na produção probatória viola a garantia da imparcialidade. Se questionará se a garantia da imparcialidade requer a absoluta passividade do juiz no desenvolvimento do debate contraditório ou se, pelo contrário, se trata de uma exigência derivada de uma determinada concepção do modelo contraditório. As respostas que apresentaremos a tais questões incidirão diretamente na valoração da posição do julgado em relação à prática da prova, se ela deve ser excluída ou limitada, ou se não afeta a imparcialidade, o que é uma questão relacionada aos fins do processo. Para isso, se analisará previamente o conceito de imparcialidade e suas diversas definições.

Palavras-Chave: imparcialidade judicial; independência; prova; processo penal; sistemas processuais; sistema acusatório; modelo contraditório; sistema adversarial. 


\section{INTRODUCCIÓN}

Es difícil exagerar la importancia de la imparcialidad como principio integrante del concepto de justicia y, por tanto, de la función jurisdiccional. De hecho, la configuración de la entera estructura del proceso, como también la del propio estatuto jurídico de los jueces, está concebida para garantizar a los justiciables el derecho a un juicio imparcial. Las conductas o actuaciones que pueden suscitar dudas acerca de si el juez está en condiciones de llevar a cabo su función de manera objetiva y ateniéndose exclusivamente a la ley, son de muy diversa índole.

Una de las situaciones que genera mayor debate en cuanto a su incidencia en la imparcialidad judicial —o en la imagen de imparcialidades la que se refiere al rol del juez o tribunal en el debate contradictorio ${ }^{2} \mathrm{y}$ a su actuación en la práctica de la prueba ${ }^{3}$. Para valorar la imparcialidad de un juez concreto, el legislador actúa de un doble modo. Por un lado, identifica determinadas circunstancias, objetivamente determinadas, que considera causas de abstención o recusación del juez porque representan un riesgo para la imparcialidad o su apariencia. Por otro lado, regula el propio modelo y estructura del proceso penal de manera que prevea, evite, minimice o excluya que las funciones atribuidas al juez menoscaben su posición como tercero imparcial. El presente trabajo se centra en un concreto aspecto de este segundo modo de actuar del legislador.

2 Sobre el sistema contradictorio vid. el interesante capítulo de G. Illuminati, "Modello processuale accusatorio e sovraccarico del sistema giudiziario", en el cual el autor no sólo realiza un análisis conceptual de este sistema y sus diferencias con el sistema adversarial de los Estados Unidos, sino que además introduce una visión realista del funcionamiento del proceso penal contradictorio italiano.

3 Vid., entre otros, J. PICÓ I JUNOY, "Reflexiones en torno a la cuestionada iniciativa probatoria del juzgador penal”, Revista Justicia 1-1996, pp. 158159; J.A. DÍAZ CABIALE, Principios de aportación de parte y acusatorio: la imparcialidad del juez, Granada, 1996, p. 199 y ss. En la doctrina brasileña: M. ZILLI. A Iniciativa Instrutória do Juiz no Processo Penal. São Paulo, 2003; V. VASCONCELLOS. O 'Sistema Acusatório' do Processo Penal Brasileiro: Apontamentos Acerca do Conteúdo da Acusatoriedade a partir de Decisões do Supremo Tribunal Federal. Direito, Estado e Sociedade, n. 47, p. 181-204, jul./dez. 2015; J. COUTINHO. O papel do novo juiz no processo penal. In: J. COUTINHO (coord.). Crítica à Teoria Geral do Direito Processual Penal. Rio de Janeiro, 2001. 
Antes de entrar en materia, conviene recordar algo bien conocido pero no pocas veces soslayado en la práctica. La garantía de la imparcialidad no persigue cuestionar en cada caso la capacidad de jueces y magistrados para mantener un distanciamiento emocional de los asuntos que son llamados a decidir; ni tampoco poner en duda su sometimiento estricto a la ley y su voluntad de aplicar la ley en términos de igualdad. En otras palabras, no se trata, con las medidas de garantía de la imparcialidad, de hacer un juicio moral implícito sobre la persona del juez. Por ello, verificar la existencia de una causa que afecta a la imparcialidad judicial no equivale a una afirmación de parcialidad de un juez concreto, sino que implica simplemente constatar que quizás "puede temerse que sea iudex suspectus"4.

Como ya he indicado, la delimitación legal de las funciones del juez en el desarrollo del proceso debe tener por finalidad, entre otras, lograr que dichas funciones sean ejercidas con las máximas garantías de imparcialidad, y también que esa imparcialidad se vea reflejada externamente. Es decir, que el juez no sea parte en el propio enjuiciamiento y tampoco sea percibido como tal. A ello se encaminan precisamente el modelo acusatorio con dualidad de partes; la no iniciación del proceso por parte del juez (nemo iudex sine actore); o el derecho al juez no prevenido, que impide la coincidencia de la función de instruir o investigar y de juzgar en la misma persona, esto es, que quien instruye o investiga no asuma posteriormente las funciones de juzgar. Todo esto es bien conocido y, en la medida en que existe consenso en cuanto a su importancia para la configuración del proceso penal, no es necesario analizarlo aquí de nuevo.

Sí hay, en cambio, una cuestión concreta que sigue siendo controvertida, tanto por parte de la doctrina como de la jurisprudencia: la relativa a la intervención del juez penal en relación con la prueba. Lo que en sustancia se discute es si la imparcialidad requiere la absoluta pasividad del juez en el desarrollo del debate contradictorio; es decir, si su intervención en ese debate con el fin de aclarar los hechos, cuestionar la veracidad de las declaraciones o valorar la credibilidad de los testigos, 4 Así la sentencia del Tribunal Supremo (STS) español de 21 de octubre de
1986 (RAJ 5714). 
implica no sólo una quiebra de la concepción del modelo contradictorio sino también de la propia garantía de imparcialidad.

En torno a esta cuestión, precisamente, se ha elaborado el presente trabajo, que pretende clarificar si reconocer al juez determinados poderes de intervención en la práctica de la prueba atenta contra la garantía de la imparcialidad. ¿Puede el juez formular preguntas a los testigos o interrogar al acusado sin perder su imparcialidad? ¿Entrañaría tal actuación riesgos para la imparcialidad del tribunal o para su apariencia? ¿Puede quizás afirmarse que la defensa a ultranza de que el juez ha de mantener una actitud pasiva se basa en una cierta concepción del modelo acusatorio más que, en rigor, en la garantía de la imparcialidad? Las respuestas que demos a estas cuestiones incidirán directamente en cómo se configure la posición del juez en relación con la práctica de la prueba, y por tanto en qué medida ha de excluirse o limitarse su intervención en la misma durante el desarrollo del juicio oral.

Es bien conocido que, en materia de imparcialidad judicial, existe una abundante literatura jurídica, tanto desde la perspectiva procesal como del derecho constitucional y la filosofía del derecho. Naturalmente, sería innecesario, por reiterativo, abordar aquí el análisis del fundamento constitucional o de la relevancia de la imparcialidad para la función jurisdiccional. Pero es inevitable que, para responder a las cuestiones antes mencionadas, partamos de un concepto de imparcialidad relativamente perfilado. A ello dedicaré el siguiente epígrafe, que, aunque extenso, en realidad trata de sintetizar una temática de enorme complejidad ${ }^{5}$.

A continuación argumentaré que la intervención del juez en el debate contradictorio con objeto de clarificar los hechos aportados por las partes en el juicio oral, a mi entender, no tiene necesariamente que desterrarse por motivos basados en el derecho a un juez imparcial;

5 En este trabajo me limito a abordar la imparcialidad que se exige a los jueces profesionales, siendo conscientes de que muchas de las afirmaciones pueden verse moduladas en relación con el tribunal del jurado formado por ciudadanos legos, en los que el sexo o la raza pueden, en determinadas circunstancias, ser invocados como causas de recusación de los miembros de alguno de los miembros. Acerca de la imparcialidad de los miembros del jurado, vid. en general, E. VALLINES GARCÍA, Instrumentos para garantizar la imparcialidad e independencia de los jurados, Cizur Menor, 2008, pp. 26 y ss. 
y que tampoco la noción de un juez más “inquisitivo”, de por sí, incide negativamente en la imagen de imparcialidad. No abordaré el alcance del contradictorio en la fase de instrucción que será objeto de análisis en otro articulo del dossier. ${ }^{6}$

\section{LOS PERFILES ESENCIALES DE LA IMPARCIALIDAD}

\section{AproximACIÓN A Un CONCEPTO COMPLEJO: OBJETIVIDAD, NEUTRALIDAD, PARCIALIDAD E INDEPENDENCIA}

La imparcialidad es un principio nuclear de la impartición de justicia, sin cuya existencia no puede hablarse propiamente de un proceso judicial ${ }^{7}$. Con razón afirma Goldschmidt que resulta extraño que no se la incluya siempre entre los principios fundamentales del proceso, pues "la justicia se basa en la imparcialidad de las personas que intervienen legalmente en la resolución de la causa" ${ }^{\text {. }}$

Como recuerda Rawls, el núcleo del concepto mismo de justicia es la fairness, que implica imparcialidad o equidad, requiere la eliminación de distinciones arbitrarias y, por tanto, está estrechamente ligada a la igualdad $^{9}$. Si esto es aplicable al concepto de imparcialidad en abstracto, también lo es al proceso, que será justo si es imparcial, y por tanto si satisface los principios que cada una de las partes podrían proponerse recíprocamente y aceptar mutuamente ${ }^{10}$.

6 Al respecto vid. el capítulo de S. RUGGERI, en este mismo volumen, "Equality of arms, impartiality of the judiciary and the role of the parties in the pre-trial inquiry: the perspective of the Italian criminal justice”. Aunque se centra en el proceso italiano y su evolución, el análisis de los principios tiene validez general.

7 Entre otros, M. CAPPELLETTI, "Fundamental Guarantees of the parties in the civil proceedings (General Report) Cappelletti, en Fundamental Guarantes (con D. Tallon), Milano 1972, p. 664 . En igual sentido S. COTTA, "L'istituzione giudiziaria tra diritto e politica”, Riv. Diritto Civ., 1984-I, pp. 430 y ss.

8 W. GOLDSCHMIDT, "La imparcialidad como principio básico del proceso", Rev. Dcho. Proc., 1950-2, pp. 186-187.

9 J. RAWLS, A Theory of Justice, Oxford 1999 (revised ed.), pp. 10 y ss.

10 Ibidem, pp. 47 y ss. 
Tan trascendente es esta "exigencia básica del proceso debido" que "sin juez imparcial no hay propiamente proceso jurisdiccional"11. La imparcialidad se considera inmanente al propio concepto de juez ${ }^{12}$, según lo refleja la máxima nemo judex in causa sua. Expresivamente lo ha indicado el Tribunal Constitucional español al afirmar que "la nota de imparcialidad forma parte de la idea de juez en la tradición constitucional”"13.

La imparcialidad aparece con frecuencia unida a la independencia en los instrumentos internacionales, en los cuales se alude al derecho a "un juez independiente e imparcial" (e-g- art. 6.1 CEDH). Independencia e imparcialidad son dos principios diferentes pero estrechamente vinculados y complementarios. La independencia judicial excluye toda subordinación o dependencia respecto de otros poderes del Estado, y también respecto de cualquier criterio distinto del que se establece en la ley ${ }^{14}$. Pero la independencia tiene en realidad carácter instrumental: no constituye un fin en sí mismo, sino que se justifica en la medida en que sirve a la realización del derecho y a la paz jurídica de forma imparcial $^{15}$. Esta conexión intrínseca entre independencia judicial y realización del principio de legalidad aparece reiteradamente en la doctrina, tanto constitucionalista como procesalista ${ }^{16}$. Y, si no está garantizado

11 Así, entre otras SSTC 60/1995, de 8 de mayo; 11/2000, de 17 de enero; y 151/2000, de 13 de junio. Vid., L. BACHMAIER, Imparcialidad judicial y libertad de expresión de Jueces y Magistrados. Las Recusaciones de Magistrados del Tribunal Constitucional, Cizur Menor, 2008, p. 19.

12 R. JIMÉNEZ ASENSIO, Imparcialidad judicial y derecho al juez imparcial, Cizur Menor 2002, pág. 59.

13 STC 162/1999, de 27 de septiembre.

14 Así, por ejemplo, en los "Principios básicos relativos a la independencia de la judicatura”, adoptados por el Séptimo Congreso de las Naciones Unidas sobre Prevención del Delito y Tratamiento del Delincuente, celebrado en Milán del 26 de agosto al 6 de septiembre de 1985, y confirmados por la Asamblea General en sus resoluciones 40/32 de 29 de noviembre de 1985 y 40/146 de 13 de diciembre de 1985.

15 Así, por ejemplo, F. BAUR, Justizaufsicht und richterliche Unabhängigkeit, Tübingen 1954, p.17. Sobre esta conexión en relación con el TPI, vid. más adelante el trabajo de A.BELTRÁN MONTOLIU, "Imparcialidad judicial y actividad probatoria en la Corte Penal Internacional".

16 Entre otros vid., D. SIMON, La independencia del Juez (trad. de C. Ximénez-Carrillo), Barcelona 1985, p.10; J.L. REQUEJO PAGÉS, Jurisdicción e independencia judicial, Madrid 1989, p. 116; J. MONTERO AROCA, Independencia 
el principio de legalidad, tampoco lo estará el de la imparcialidad y el de la igualdad ante la ley.

Por otro lado, hay una clara relación entre la imparcialidad y el derecho al juez legal o derecho al juez predeterminado por la ley ${ }^{17}$ : la predeterminación legal del órgano judicial constituye una garantía de la independencia y de la imparcialidad judicial ${ }^{18}$.

Con frecuencia, la primera aproximación al concepto de imparcialidad se centra en la exigencia de que el juez no sea parte en el proceso, que sea un tercero ajeno a la disputa: un tercero que no sea parte en el conflicto y que ocupe una posición trascendente respecto de las partes ${ }^{19}$. Junto a ello se destaca que la imparcialidad exige que el juez en su decisión no tome partido a favor de ninguna de las partes. Es decir, que sea ajeno a los intereses de las partes: lo que la doctrina italiana ha denominado terzietà o estraneità del giudice nei confronti degli interessi in causa $^{20}$, traducido como desinterés objetivo. Ello significa que no tenga relaciones con ninguna de las partes y que no realice actos que pongan

y responsabilidad del juez, Madrid 1990, p. 119; J.F. LÓPEZ AGUILAR, La justicia y sus problemas en la Constitución: justicia, jueces y fiscales en el Estado Social y Democrático de Derecho, Madrid 1996, p.112 y ss.; I. VALLDECABRES ORTIZ, La imparcialidad del Juez y medios de comunicación, Valencia 2004, pp. 127 y ss.

Vid. STEDH Moiseyev v. Russia, Appl. No. 62936/00, de 9 de octubre de 2008.

El principio de predeterminación legal tiene su origen en el sistema penal de las monarquías absolutas, contra el sistema de delegaciones y avocaciones y como reivindicación de estabilidad de los jueces. Con la implantación de un sistema de división de poderes, la predeterminación legal adquiere significación como garantía de la independencia de los jueces. Vid. I. VALLDECABRES ORTIZ, ob.cit., p. 140. Vid. también: G. BADARÓ. Juiz Natural no Processo Penal. São Paulo: RT, 2014.

19 Así, por ejemplo, las SSTC 44/1985, 137/1994 y 60/1995. Vid. también, entre otros, J. MONTERO, Sobre la imparcialidad del juez y la incompatibilidad de funciones procesales, Valencia 1999, pp. 186-187.

20 Vid. P. CALAMANDREI, Processo e democrazia, Padova 1954, p. 69. En el mismo sentido A. ARIAS DOMÍNGUEZ, La abstención y la recusación de jueces y magistrados, Madrid 1999, p. 29, "que sus intereses no concurran con ninguna de las partes antagónicas del conflicto”. J. MONTERO AROCA, ob. ult. cit., p. 187, citando a Wach, señala que además de no ser parte, la imparcialidad implica que "el juez no sirve a la finalidad subjetiva de alguna de las partes en un proceso.” 
de manifiesto una previa toma de posición respecto del asunto llamado a decidir. ${ }^{21}$ Dicho de otro modo: una actitud de neutralidad.

La diversidad de acepciones y notas características que se atribuyen a la imparcialidad se refleja tanto en la doctrina como en la jurisprudencia ${ }^{22}$.

A título de ejemplo, y sin ánimo de exhaustividad, la imparcialidad se ha definido: como un requisito de idoneidad ${ }^{23}$; de legitimación del juez ${ }^{24}$; si concurre una causa de abstención o recusación, como un supuesto excepcional de falta de legitimación del juez ${ }^{25}$; como una cualidad inseparable a la idea de juez ${ }^{26}$; como una de las garantías más firmes de una decisión justa incluida dentro del derecho al proceso debido ${ }^{27}$; como una manifestación de la independencia judicial en el caso concreto ${ }^{28}$; como una actitud ${ }^{29}$; como un estado de ánimo según el cual el juez a la hora de juzgar deja al margen cualquier consideración subjetiva; como objetividad consistente en la vocación de ser fiel a la ley y a los valores del ordenamiento jurídico ${ }^{30}$; como neutralidad, desinterés, ajeneidad o como actitud de rectitud.

Si vamos a un contexto jurídico muy diferente, como es el norteamericano, observamos posiciones similares en materia de imparcialidad y neutralidad. Así, el Model Code of Judicial Conduct de la American Bar Association afirma que el término imparcialidad denota ausencia de

21 Sobre esto, en la doctrina brasileña: A. MAYA. Imparcialidade e Processo Penal da Prevenção: da competência ao juiz das garantias. Rio de Janeiro, 2011.

22 Vid. L. BACHMAIER, op. cit., pp. 20-21.

23 F. CARNELUTTI, Diritto e processo. Trattato del processo civile, Napoli 1958, p. 74 .

24 F. CARNELUTTI, Sistema di diritto processsuale civile, t. IV, Padova 1936, p. 183; V. GIMENO SENDRA, "Poder judicial, potestad jurisdiccional y legitimación de la actividad judicial”, Rev. Dcho. Proc., 1978, p. 336 y ss.; R. SERRA CRISTÓBAL, La libertad ideológica del juez, Valencia 2004, pp.27 y ss.

C. FARANDA, La capacità del giudice, Milano 1958, pp. 42-43.

P. CALAMANDREI, Proceso y democracia, Buenos Aires 1960, p. 60.

I. ESPARZA LEIBAR, El principio del proceso debido, Barcelona 1995, p. 216.

Así A. ARIAS DOMÍNGUEZ, La abstención y la recusación de jueces y magistrados, Madrid 1999, p. 42.

29 J. L. REQUEJO PAGÉS, Jurisdicción e independencia judicial, Madrid 1989, p. 167.

30 E. FAZZALARI, “La imparzialità del giudice”, Riv. Dir. Proc., 1972, p.195. 
prejuicio a favor o en contra de una parte en particular o de una clase de partes, así como mantener una mente abierta respecto de las cuestiones que pueden llegar a serle planteadas al juez ${ }^{31}$.

Por lo que se refiere al Tribunal Europeo de Derechos Humanos (TEDH), en numerosas sentencias se equipara la imparcialidad a objetividad y neutralidad, y se señalan como características esenciales la ausencia de prejuicios y de parcialidad ${ }^{32}$. La definición del TEDH es deliberadamente genérica y amplia, pero se concreta a través de los sistemas de control de la garantía en cada caso concreto. En todo caso, definir la imparcialidad como ausencia de parcialidad obliga a analizar qué significa la "parcialidad" en el contexto procesal.

Se entiende que existe parcialidad cuando el juez, en el desarrollo del proceso o en su decisión, favorece o tiende a favorecer a una de las partes sobre la base de argumentos ajenos al proceso y distintos de la aplicación del derecho objetivo, atentando así contra el principio de igualdad. Es decir, cuando toma partido por una de las partes por influencia de circunstancias subjetivas y ajenas al caso. Visto desde la perspectiva opuesta, la imparcialidad reclama que la decisión judicial se funde exclusivamente en las circunstancias objetivas del caso conforme a derecho, sin interferencias ajenas, sobre la base de las actuaciones realizadas en el proceso. Además, la imparcialidad excluye la existencia de una previa disposición de ánimo en el juez que le haga inclinarse a favorecer -o perjudicar-a una de las partes $^{33}$.

31 ABA Model Code of Judicial Conduct 2007: "Impartial," "impartiality," and "impartially"mean absence of bias or prejudice in favor of, or against, particular parties or classes of parties, as well as maintenance of an open mind in considering issues that may come before a judge. See Canons 1, 2, and 4, and Rules 1.2, 2.2, 2.10, 2.11, 2.13, 3.1, 3.12, 3.13, 4.1, and 4.2. Accesible en: https://www.americanbar.org/content/dam/aba/migrated/judicialethics/ ABA_MCJC_approved.authcheckdam.pdf

32 Entre otras vid., Piersack v. Belgium de 1 de octubre de 1982; Hauschildt $v$. Denmark, de 24 de mayo de 1989; Nortier v. Neatherlands, de 24 de agosto de 1993; Ferrantelli and Santangelo v. Italy, de 7 de agosto de 1996; Buscemi v. Italy, de 16 de septiembre de 1999; McGonnell v. United Kingdom, de 8 de febrero de 2000; Morel v. France, de 6 de junio de 2000; Ranson v. United Kingdom, de 2 de septiembre de 2003 ; Kyprianou v. Cyprus de 27 de septiembre de 2004.

33 Vid. J. RIEDEL, Das Postulat der Unparteilichkeit des Richters, Berlin 1980. 
Son dos, por tanto, los elementos que, en principio, permiten identificar una actuación parcial ${ }^{34}: 1$ ) la influencia de elementos subjetivos y ajenos al caso en el desarrollo del proceso o en la decisión judicial; $y$ 2) que, sobre la base de esos elementos, se confiera o tienda a conferir un trato desigual a las partes al margen del estricto sometimiento a la ley. Por otra parte, para diferenciar una actuación parcial de una mera infracción procesal que favorece a una de las partes, ha de atenderse a la actitud interna del juez, proclive a un tal trato de favor. En la práctica, para evitar difíciles averiguaciones, y una prueba aún más difícil, sobre el motivo que fue causa de la actuación procesal, lo determinante será cómo se perciba externamente tal actuación del juez.

De lo expuesto hasta ahora podríamos concluir que los tres elementos característicos de una actuación parcial son: el ánimo interno del juez, la incidencia de elementos ajenos al proceso, y la consecuencia de tender a favorecer a los intereses de alguna de las partes ${ }^{35}$.

Por lo demás, el hecho de que el juez sea consciente o no de su tendencia o predisposición a favorecer a una de las partes no es decisivo para que se aprecie una actuación parcial ${ }^{36}$.

2. IMPARCIALIDAD OBJETIVA, IMAGEN DE IMPARCIALIDAD Y ESTRUCTURA DEL PROCESO

El Tribunal Europeo de Derechos Humanos, desde la sentencia Piersack $^{37}$, y asumiendo una clasificación existente en la jurisprudencia de los tribunales del Reino Unido (análoga a la distinción entre actual bias

34 Vid. L. BACHMAIER, op. cit., p. 23.

35 Así J. RIEDEL, ob. cit. p. 20; R. JIMÉNEZ ASENSIO, Imparcialidad judicial y derecho al Juez imparcial, cit., p. 71.

36 Así sucede, por ejemplo, cuando existen prejuicios de los cuales el propio juez no es consciente, pero que constituyen una posición o convicción interna que, al margen de los elementos objetivos del caso, le hacen tender a beneficiar o perjudicar a una de las partes. Vid. C. STEMMLER, Befangenheit im Richteramt. Eine systematische Darstellung der Ausschließungs- und Ablehnungsgründe unter Berücksichtigung des gesetzlichen Richters als materielles Prinzip, Tübingen 1975, pp. 99 y ss.

37 Piersack v. Belgium, de 1 de octubre de 1982. 
y apparent bias $^{38}$ ), se ha referido a la imparcialidad subjetiva y objetiva. Para el Tribunal de Estrasburgo, la aproximación subjetiva a la imparcialidad se centraría en la conducta del juez en el caso concreto, con el fin de determinar si tiene un prejuicio real, averiguar sus convicciones personales, y analizar su actitud personal frente al asunto ${ }^{39}$.

Frente a esta dimensión subjetiva, el control de la dimensión objetiva de la imparcialidad tomaría en cuenta no tanto los posibles prejuicios del juez, sino las circunstancias del caso, con el fin de analizar si ofrecen garantías suficientes para excluir legítimas sospechas de parcialidad ${ }^{40}$. El análisis de la dimensión objetiva no cuestiona la actitud del juez ni su integridad, sino que se centra en determinar si un concreto juez por razón de sus funciones, su situación, o sus relaciones o intereses respecto de las partes o del objeto del proceso, puede generar dudas objetivas acerca de la imparcialidad.

A este respecto, es importante no olvidar que la propia estructura del proceso es la garantía básica de la imparcialidad. Su configuración legal ha de posibilitar que la imparcialidad sea efectiva, que no permita que una de las partes se vea favorecida frente a la otra, que el debate sea justo ${ }^{41}$. Cuando no sucede así, la igualdad podría verse comprometida (aunque ello no constituya de suyo y necesariamente una actuación parcial). Asimismo, basta con que las circunstancias externas o la propia estructura del proceso generen un riesgo objetivo para cuestionar la existencia real de imparcialidad, pues no sólo es importante evitar que algún juez sea parcial, sino también que el ciudadano pueda confiar en que la justicia se aplicará en su caso de manera imparcial.

Se advierte así que la valoración objetiva de los hechos que pueden menoscabar la imparcialidad judicial está en estrecha relación con la

38 Vid. G. SLAPPER and D. KELLY, Sourcebook on the English Legal System, London 2001, pp. 564-565.

39 Entre otras, vid., Hauschildt v. Denmark, de 2 de mayo de 1989, Thoman $v$. Switzerland, de 10 de junio de 1996, Ferrantelli and Santangelo $v$. Italy, de 7 de agosto de 1996. Vid. también M. KUIJER, The Blindfold of Lady Justice. Judicial Independence and Impartiality in Light of the Requirements of Article 6 ECHR, Leiden 2004, pp. 303-306; K. REID, A practitioner's Guide to the European Convention on Human Rights, London, 2008, p.130.

40 Entre otras, De Cubber v. Belgium, de 26 de octubre. Vid. K. REID, ob.cit., p.130.

41 Vid. STC 151/2000, de 13 de junio. 
idea de que la apariencia de imparcialidad es necesaria para la confianza del ciudadano en la justicia; y que, por ello, la imagen de imparcialidad judicial debe protegerse como un valor esencial de la propia sociedad. Es lo que transmite la máxima inglesa de que no sólo es importante que se haga justicia sino que se vea esa justicia ${ }^{42}$. En la misma dirección, el TEDH ha sostenido reiteradas veces que las apariencias son relevantes, porque está en juego la confianza que, en una sociedad democrática, los ciudadanos deben tener en sus tribunales de justicia ${ }^{43}$. La imparcialidad está directamente conectada con la imagen del poder judicial como institución y es esencial para la legitimidad de la justicia en general y del Estado en particular ${ }^{44}$.

Pese a todo, lo cierto es que, la diferenciación entre las dimensiones subjetiva y objetiva no tiene demasiada relevancia práctica: la garantía de la imparcialidad opera de ordinario sobre causas que se ya han sido objetivadas, bien por la ley o por la jurisprudencia, presumiendo que inciden -o pueden incidir- en el ánimo o actitud del juzgador.

Todo lo anterior podría llevar a la conclusión de que lo importante, en relación con el desarrollo de la función jurisdiccional, es la

42 R. v. Sussex Justices ex $p$ McCarthy: "it is of fundamental importance that justice must not only be done but should manifestly and undoubtedly be seen to be done". La distinción entre el aspecto subjetivo y objetivo de la imparcialidad, también fue asumida por el Tribunal Constitucional español, pero dándole un significado diferente, al distinguir entre las causas que afectan a las relaciones con las partes - dimensión subjetiva- y las que afectan a las relaciones con el objeto del proceso - dimensión objetiva-. La diversa acepción asumida por el Tribunal Constitucional y el TEDH, lejos de contribuir a clarificar la noción de imparcialidad ha sido fuente de confusiones o malentendidos. R. JIMÉNEZ ASENSIO, Imparcialidad judicial y derecho al juez imparcial, cit., p. 198.

43 En numerosas sentencias del TEDH se repite - casi siempre de manera literal- la misma afirmación: “(...) even appearances may be of certain importance. What is at stake is the confidence which the courts in a democratic society must inspire in the public".

44 Vid. el Informe 18(2015) del Consejo Consultivo de Jueces Europeos del Consejo de Europa "La posición del poder judicial y su relación con los demás poderes del Estado en una democracia moderna” de 16 de octubre de 2015, accesible en: http://www.poderjudicial.es/cgpj/es/Temas/Relaciones-internacionales/Relaciones-internacionales-institucionales/Europa/ Consejo-Consultivo-de-Jueces-Europeos 
apariencia de imparcialidad; y que lo mismo debería predicarse respecto a la estructura del proceso y los poderes de actuación del juez ${ }^{45}$. A mi modo de ver, no cabe duda de que, para garantizar una decisión basada en justicia, lo que importa es la imparcialidad real y no su mera apariencia. Pero, como ya he señalado antes, normalmente esa garantía puede llevarse a cabo de manera preventiva sólo centrándose en las apariencias, es decir, mediante la presunción de que ciertos hechos pueden ser considerados a priori como factores de riesgo para la imparcialidad. No olvidemos que la imparcialidad es característica que ha de tutelarse respecto de la propia administración de justicia en el conjunto de sus instituciones, y no sólo respecto de la actuación - y actitud- de un juez ante un caso concreto. La confianza en la justicia es decisiva para la seguridad de todo el ordenamiento jurídico, y por ello la imparcialidad judicial adquiere un significado trascendental para el conjunto del sistema institucional ${ }^{46}$.

\section{LOS FACTORES SUBJETIVO-PERSONALES DEL JUEZ Y LA DIFERENCIA CON LA QUIEBRA} DE LA IMPARCIALIDAD

Antes he definido la actuación imparcial como aquella en la que el desarrollo del proceso y la decisión judicial se basan en la estricta aplicación de la ley, sin que incidan elementos subjetivos ajenos al objeto del proceso a favor o en contra de una de las partes. Esa definición, sin embargo, requiere ser matizada, pues toda sentencia judicial, en la medida en que es la expresión de un quehacer humano, está influida por elementos subjetivos y en ella se refleja de manera más o menos intensa la personalidad del juez ${ }^{47}$.

45 En este sentido el Magistrado De Meyer en su voto particular en el caso $\mathrm{Pa}$ dovani $v$. Italy, de 26 de febrero de 1993, ha llegado a expresar en relación con la imparcialidad judicial que quizás se estaba dando más importancia a las apariencias que a la propia realidad.

46 Así, R. JIMÉNEZ ASENSIO, ob.cit., p. 72. Imparcialidad en este contexto institucional se refiere a la neutralidad que los jueces - y por tanto la institución que representan- deben mantener frente a los demás poderes del Estado, puesto que esa falta de neutralidad minaría la requerida confianza de la sociedad en el poder judicial

47 L. BACHMAIER, op. cit., p. 31. Así también R. JIMÉNEZ ASENSIO, ob. cit., p. 89. 
Toda aplicación de la ley requiere una labor de interpretación y valoración, que se manifiesta con más intensidad en supuestos de lagunas legales, de aplicación de normas generales, o ante normas que expresamente confieren al juez un margen de decisión discrecional ${ }^{48}$. Las normas deliberadamente abiertas confieren flexibilidad a las leyes en una sociedad cambiante y permiten que el juez adapte la regulación a las circunstancias concretas en cada situación y momento. A medida que la ley deja mayor margen de discrecionalidad, pierde objetividad y se relativiza con un elemento subjetivo que podría ir en detrimento de la neutralidad judicial, así como en el distanciamiento del juez del caso concreto y de las partes del proceso ${ }^{49}$. En otras palabras, mientras más amplio es el ámbito de discrecionalidad judicial, mayor es el riesgo de que en la decisión del juez influyan elementos externos a favor o en contra de alguna de las partes.

El elemento valorativo también está presente en el desarrollo del proceso, por lo que en todo juicio jurisdiccional influyen factores individuales y sociales de diversa índole que, en conjunción con lo dispuesto en la ley, conformarán la decisión judicial ${ }^{50}$. Como dijo en su día Carnelutti citando a Capograssi, garantizar una objetividad total sólo sería posible si el juez estuviera "assente", en el sentido de que no tuviera conocimientos de ningún tipo que provocaran una predisposición ${ }^{51}$; en la medida en que uno está "presente", toma conocimiento de los hechos, se involucra en ellos e irremediablemente tiende a participar a favor o en contra de una de las partes ${ }^{52}$.

48 En igual sentido M. KUIJER, ob.cit., p. 315.

49 Así K.A. BETTERMANN, "Vom Sinn und von den Grenzen der richterlichen Unabhängigkeit”, en Die Unabhängigkeit des Richters, Köln, 1969, p. 53.

50 O. BACHOF, Grundgesetz und Richtermacht, Tübingen 1959, p. 35; R. WASSERMANN, Die richterliche Gewalt. Macht und Verantwortung des Richters in der modernen Gesellschaft, Heidelberg 1985, pp. 159 y ss.

51 F. CARNELUTTI, ob. cit., pp. 75-76: "Un nostro grande filosofo del diritto diceva che il giudice, rispetto a ciò che gli si chiede di giudicar, deve essere, in principio, assente, volendo dire non tanto che non ne sa quanto che non ne deve sapere nulla, una tabula rasa."

52 Idem., "Il vero è che nessuno di noi può assistere ai fatti altri, che vuol poi dire mescolarsi alla vita degli altri, senza proteggiate o, almeno, se vogliamo trovare un verbo più discreto, senza sbilanciarsi." 
Es en efecto mucho más realista partir de que todo juez es un ser humano con sus convicciones, sentimientos y creencias, y que no puede operar como una suerte de máquina de administrar justicia desprovista de emociones y que, por tanto, no existe un pronunciamiento judicial que sea objetivo en términos absolutos. El ordenamiento jurídico parte de la realidad de que la personalidad del juez está marcada por múltiples factores, por más distanciamiento emocional que mantenga con el asunto que es llamado a decidir, y no obstante la ausencia de un interés concreto en el resultado del proceso. Son los denominados elementos estructurales de la personalidad, también llamados elementos subjetivo-personales o condicionamientos sociales e ideológicos.

La proximidad entre estos elementos subjetivo-personales y la parcialidad es evidente. Los elementos estructurales de la personalidad del juez no pueden considerarse como elementos ajenos a las circunstancias del proceso y por tanto su presencia no puede calificarse como contraria a la garantía de la imparcialidad ${ }^{53}$. Están implícitos en la propia función jurisdiccional y el juez no puede prescindir de los mismos al elaborar su juicio. La función de aplicar el derecho, la elección de la norma aplicable, y la interpretación jurídica conllevan un margen de discrecionalidad, que en muchos casos no sólo está admitida y prevista legalmente, sino que resulta necesaria. En ese margen de elección, que es consustancial al desarrollo de la función jurisdiccional, inevitablemente inciden las propias concepciones de la persona del juez, y el hecho de que su elección perjudique a una de las partes no significa que esa opción sea una decisión parcial ${ }^{54}$.

La existencia de un interés general en la materia a decidir es uno de los elementos que pueden configurar la estructura subjetivo-personal del juez, sus simpatías y antipatías o su tendencia a favorecer o perjudicar la posición de una de las partes. Por ejemplo, aquellos casos en que el juez

53 J. RIEDEL, ob. cit., pp. 31 y ss.

54 J. RAWLS, Justicia como equidad, Madrid 1999, pp. 62-63, quien en relación con el juez moral afirma que ha de "de considerar las cuestiones con mente abierta y, en consecuencia, aunque pueda tener ya formada una opinión sobre un problema, estar siempre dispuesto a reconsiderarla a la luz de ulteriores pruebas y razones"; y que ha de conocer sus propias preferencias emocionales, intelectuales y morales, para tenerlas en cuenta a la hora de valorar los pros y contras de cualquier cuestión sin desconocer "las influencias que el prejuicio y la predisposición ejercen incluso en sus más sinceros esfuerzos por anularlas”. 
en su condición de ciudadano particular se encuentre en una posición semejante a la que ocupa una de las partes. Esa proximidad con su propia experiencia personal puede producir que el juez se interese más por el asunto concreto y que, como consecuencia de su propia percepción y sistema de valores, vea con más simpatía una posición que la contraria.

\section{El JUEZ COMO TERCERO NO PARTE Y LA PRÁCTICA DE LA PRUEBA}

Como ya he señalado, en el postulado de la imparcialidad encontramos una concreción del principio de igualdad, de igualdad de los ciudadanos ante el Juez y de igualdad en la aplicación del derecho. La imparcialidad constituye, por tanto, una manifestación concreta del principio constitucional de igualdad ${ }^{55}$. La ausencia de parcialidad implica que los justiciables reciban por parte del Juez un trato de igualdad, no en un mero sentido formal, sino también en un sentido material; que a ambas partes les sea aplicada la ley en igualdad de condiciones y que el Juez no realice distinciones en función de situaciones o datos no contemplados en la ley, para lo cual el proceso debe articularse de tal forma que se minimicen los riesgos de posible influencia de elementos externos que aparten al Juez de la aplicación del derecho sin influencias externas contrarias a la igualdad.

La exigencia básica para garantizar la imparcialidad es la de que el Juez no sea parte: nemo iudex in causa sua. El concepto de imparcialidad aparece inescindiblemente vinculado a la exigencia de que el Juez no sea parte en el proceso. No ser Juez en la propia causa es un principio irrenunciable del proceso y, como señalan los ingleses, "the maxim that no man is to be judge in his own cause should be held sacred" ${ }^{6}$.

Pero, ¿qué se entiende por "no ser parte"? La exigencia de "no ser parte" como premisa de la imparcialidad, se utiliza en un sentido estricto o formal, pero también en un sentido amplio, como tercero totalmente ajeno a los sujetos y a la disputa que ha de resolver ${ }^{57}$.

55 Vid. J.RIEDEL, ob. cit., pp. 14 y ss.

56 S.H. BAILEY, J. CHING, M. GUNN y D. ORMEROD, Smith, Bailey \& Gunn on the Modern English System, London, 2002, p. 281.

57 Así, las SSTC 299/1994, de 14 de noviembre; 154/2001, de 2 de julio; o $38 / 2003$, de 27 de febrero, entre otras aluden a la exigencia de que el Juez sea un tercero ajeno a las partes y al objeto. 
No ser parte, en este plano amplio, coincide con la exigencia moral de que el Juez "no tome parte" a favor o en contra de ninguno de los sujetos del proceso. Jurídicamente esa rectitud moral pretende preservarse mediante un distanciamiento emocional del Juez, para lo cual se requiere como premisa básica, pero no única, que el Juez ocupe la posición de tercero en el proceso. La expresión "no ser parte" en este sentido amplio implica en primer lugar no ser parte en sentido formal, y en segundo lugar, no estar condicionado subjetivamente en la emisión del juicio jurisdiccional. Pero, como puso de relieve Carnelutti ${ }^{58}$, un Juez como persona humana "un uomo che non sia parte non esiste". La reflexión de este autor parte de reconocer que la "res iudicanda" más que un juicio sobre una "cosa" implica "iudicare un altro uomo", por lo que el Juez es imposible que deje de ser parte en sentido lato, pues es un hombre al igual que las partes del proceso.

En las definiciones de la imparcialidad suele encontrarse la referencia a dos condiciones, a la de no ser parte y a la de mantener una actitud objetiva. En ese contexto, la exigencia de "no ser parte" se refiere a la posición que el Juez debe ocupar en el proceso, de tal manera que no coincida con la de las partes ${ }^{59}$. Pero, zintervenir en la práctica de la prueba le convierte en parte?

\section{FAcultades PROBATORIAS DEL TRIBUnAL E IMPARCIALIDAD}

Una vez definido el concepto y las garantías de imparcialidad en el proceso penal, es necesario plantearse si la misma exige que el juez se mantenga absolutamente pasivo ante el debate contradictorio o si, por el contrario, su intervención más o menos activa en la práctica de la prueba en el juicio oral, es incompatible con la garantía de la imparcialidad ${ }^{60}$.

${ }_{58}$ F. CARNELUTTI, Diritto e processo, cit., pp. 73-75.

59 En igual sentido, R. JIMÉNEZ ASENSIO, "Imparcialidad es una posición orgánica o estructural de un Juez”, p. 71; A. ARIAS DOMÍNGUEZ, La abstención y recusación de Jueces y Magistrados, cit., p. 30 es "no ser formalmente parte".

${ }_{60} \mathrm{El}$ análisis de la imparcialidad judicial y la práctica de la prueba en el proceso ante el Tribunal Penal Internacional, es objeto del trabajo de A. BELTRÁN MONOTOLIÚ en este mismo volumen. 
Al hablar de iniciativa probatoria del juez, es necesario diferenciar entre intervenciones de muy distinta intensidad ${ }^{61}$, desde la posibilidad de ordenar de oficio pruebas no solicitadas por las partes, a la formulación de preguntas a los testigos, o la intervención más leve de sugerir a las partes que aporten determinada prueba. Si bien introducir en el proceso penal pruebas no solicitadas por las partes podría resultar en algunos supuestos discutible desde el punto de vista de la garantía de la imparcialidad, en particular, si el órgano juzgador llevara a cabo una búsqueda de esos elementos de prueba, permitir que el tribunal intervenga en las pruebas personales mediante preguntas a los testigos, peritos o al acusado, sin duda, no tiene la misma repercusión. Es en relación con este tipo de "poderes probatorios" de menor intensidad, respecto de los cuales me voy a pronunciar ${ }^{62}$.

A su vez ha de distinguirse entre el proceso penal de corte más adversarial $^{63}$, como es el proceso penal federal de los Estados Unidos de Norteamérica (USA), de los procesos de corte continental europeo. El sistema adversarial, que se caracteriza porque el proceso es cuestión de partes, la posición pasiva del juez como mero espectador del debate se ha considerado tradicionalmente como un presupuesto esencial del mismo. Siendo un pro-

61 Vid., por ejemplo, J. FERRER BELTRÁN, "Los poderes probatorios del juez y el modelo de proceso", Cuadernos Electrónicos de Filosofía del Derecho, núm. 36 (2017), pp. 88-108, pp. 97-104.

62 Conviene precisar que muchos de los estudios realizados sobre la búsqueda de la verdad y los poderes probatorios del juez se centran en el proceso civil, como por ejemplo X. ABEL LLUCH, Iniciativa probatoria de oficio en el proceso civil, Barcelona 2005; J. PICÓ i JUNOY, El juez y la prueba. Estudio de la errónea recepción del brocardo iudex iudicare debet secundum allegata et probata non secundum conscientiam y su repercusión actual, Barcelona 2007; J. FERRER BELTRÁN, Prueba y verdad en el Derecho, Barcelona 2005; o el clásico M. TARUFFO, La prova dei fatti giuridici: nozioni generali, Milano, 1992. Pero las conclusiones y afirmaciones que se realizan al discutir el principio dispositivo y el principio de aportación de parte en ese ámbito no son trasladables sin más al proceso penal, que, al margen de cómo se configuren los poderes de cada una de las partes en concreto, tiene en todo caso un marcado carácter inquisitivo -debido al más acentuado interés público presente en la aplicación del derecho penal-, sin poder prescindir en el mismo de la búsqueda de la verdad.

63 Sigo aquí el concepto de adversary que sigue M. DAMASKA, Evidence Law Adrift, New Haven, 1997, p. 74: "a system of adjudication in which procedural action is controlled by the parties and the adjudicator remains essentially passive", siguiendo a su vez la definición contenida en la Encyclopedia of Crime and Justice. 
ceso dominado por la actuación de las partes y estando dividido el proceso en dos casos -el de la acusación y el de la defensa-, una intervención por parte del juez en la aportación de la prueba, podría interpretarse como un apoyo a favor de la parte que se viera beneficiada por esa prueba ${ }^{64}$ : parece claro que la intervención del juez en el interrogatorio de testigos tiene un impacto muy diferente en un sistema donde los testigos no son testigos "de las partes”, sino de la causa. La posible percepción de parcialidad por parte del juez cuando se interroga a un testigo tiende claramente a diluirse en un sistema el cual los testigos no están vinculados a ninguna de las partes. Aunque, obviamente, si la intervención es indistinta y unas veces apoya a una parte y otras veces a la otra, ya no se vería necesariamente como una inclinación de la balanza en contra de la imparcialidad.

Atribuir a las partes el control sobre la prueba no es una consecuencia del principio de imparcialidad, sino que deriva de la concepción y fines que se atribuyen al proceso penal ${ }^{65}$. Ello no obstante, aunque el sistema de los USA haya optado por un proceso party-driven y orientado fundamentalmente a la resolución de un conflicto, la ley confiere al juez la potestad de intervenir en la cross-examination, así como ejercer cierta iniciativa probatoria, llamando de oficio a alguno de los testigos que considere relevante para determinar los hechos ${ }^{66}$. Es cierto que, en la práctica, esa facultad conviene que sea ejercida con moderación, pues de lo contrario podría verse afectada su posición neutral en el debate contradictorio, y por tanto en la imagen de imparcialidad que deben ofrecer en todo caso. Intervenir de manera decisiva en la práctica de la

64 Vid., M. DAMASKA, Evidence Law Adrift, cit., p. 82.

65 M. DAMASKA, The faces of justice and state authority. A comparative approach to legal process, New Haven 1986, pp. 5 y ss.

66 Así se dispone en las US Federal Rules of Evidence. Rule 614. "Court's Calling or Examining a Witness. (a) Calling. The court may call a witness on its own or at a party's request. Each party is entitled to cross-examine the witness. (b) Examining. The court may examine a witness regardless of who calls the witness. (c) Objections. A party may object to the court's calling or examining a witness either at that time or at the next opportunity when the jury is not present." Si bien esta intervención está prevista, también es cierto que el juez sólo debe hacer uso de ella de forma limitada y excepcional, vid., por ejemplo, H.H. HOBGOOD, "When should a trial judge intervene to question a witness?”, 3 Campbell Law Rev. (1981), pp. 69-76. 
prueba, no sólo sería contrario al modelo adversarial, sino que también podría interpretarse en ciertos casos como una inclinación a favor de la posición de una de las partes.

Por el contrario en el proceso de corte continental europeo, al estar más orientado al esclarecimiento de unos hechos y la determinación de la responsabilidad penal de los autores, el caso no se divide en dos, sino que persigue un fin único: buscar en la medida de lo posible la verdad de lo sucedido ${ }^{67}$. Lo decisivo es averiguar los hechos y para ello no es tan importante quién aporta las pruebas, siempre que se respete el marco de licitud y el derecho de defensa ${ }^{68}$.

67 No es este el lugar para analizar las complejas cuestiones filosóficas acerca del concepto de verdad. Asumiendo que la verdad como tal no es un fin alcanzable en el proceso pena, toda la estructura del proceso penal debe fomentar una aproximación a la realidad histórica de los hechos, siempre dentro del marco del respeto de los derechos fundamentales de los individuos. A mi juicio, un proceso que merezca denominarse justo debe perseguir acercarse lo más posible a la verdad de los hechos. Sobre este tema, vid. in extenso, N. GUZMÁN, La verdad en el proceso penal. Una contribución a la epistemología jurídica, Buenos Aires, 2006, en donde analiza en profundidad las diversas concepciones de la verdad, los límites del proceso y, también el contradictorio como método para el conocimiento de esa verdad, en particular pp. 148 y ss. En la doctrina brasileña: G. BADARÓ. Ônus da prova no processo penal. São Paulo, 2003. En critica a la busca de la verdad: A. LOPES JR. Direito Processual Penal. $9^{a}$ ed. São Paulo, 2012.

68 No significa lo anterior que el modelo adversarial prescinda de la verdad, sino que cada uno de los modelos elige un camino diferente para llegar a ella: investigación oficial exhaustiva de todos los hechos por parte del estado o a través de una activa investigación de cada una de las partes, aportando los hechos y medios de prueba que fundamentan su posición. En la obtención y aportación de la prueba es donde quizás se plasmen con mayor claridad las diferencias entre el modelo adversarial y el históricamente denominado modelo inquisitivo. Acerca de los diferentes modelos procesales, en particular, adversarial frente a inquisitivo, me remito a los diversos trabajos recogidos en L. BACHMAIER WINTER (ed.), Proceso penal y sistemas acusatorios, Madrid 2008. Vid. también, entre otros, M. LANGER, "In the Beginning was Fortescue: On the Intellectual Origins of the Adversarial and Inquisitorial Systems and Common and Civil Law in Comparative Criminal Procedure" en B. Ackerman, K. Ambos y H. Sikiric (eds.), Visions of Justice, Liber Amicorum Mirjan Damaska, Berlin 2016, pp. 273-299, p. 277 y ss. M. DAMASKA, “Truth in Adjudication”, (1998) 49 Hasting Law Journal, p. 289 y ss. En la doctrina brasileña: V. VASCONCELLOS. Sistemas Processuais Penais: as contribuições das visões histórica e de direito comparado para o desvelamento da essência acusatória. Revista de Estudos Criminais, v. 58, p. 127-152, 2015; M. SAAD; D. 
Por último, debe diferenciarse entre los procesos con jurado de aquellos que se desarrollan ante un tribunal formado por jueces profesionales. En el primero, no sólo debe preservarse la imagen de imparcialidad, sino que debe realizarse un esfuerzo adicional para que la posición del juez no se perciba como una suerte de guía para la formación de la convicción acerca de los hechos en las personas que forman parte del jurado. La posible "contaminación" del jurado proveniente del ámbito de las propias actuaciones judiciales -y no de elementos exteriores-, se denominan contaminaciones extrínsecas procesales. Tanto las indebidas sugerencias por parte del ministerio público, como la introducción en el juicio de prueba inadmisible, son considerados elementos que pueden incidir en la imparcialidad de los jurados y por tanto, deben ser evitadas.

Es cierto que una actuación excesivamente inquisitiva por parte del juez frente al acusado o a alguno de los testigos, podría influir en la percepción del debate por parte del jurado y, por tanto, podría incrementar el riesgo de que se vea afectada su objetividad. Ello justificaría que el juez en ese tipo de procesos se mantenga más pasivo en el desarrollo del debate contradictorio y en la práctica de la prueba. Ahora bien, si la intervención del juez se limita a formular alguna pregunta para esclarecer los hechos o clarificar las respuestas ofrecidas por los sujetos interrogados, esa intervención no parece que debiera interpretarse como un riesgo para la imparcialidad del jurado.

En este sentido es interesante constatar como Vallines, al argumentar sobre la contaminación extrínseca procesal y extraprocesal, no menciona en ningún momento la posible afectación de la imparcialidad de los miembros del jurado por la actividad probatoria llevada a cabo por el tribunal enjuiciador ${ }^{69}$.

Los argumentos que se han esgrimido para rechazar cualquier intervención por parte del juez en la prueba en los procesos con jurado, no serían válidos en aquellos procesos que se celebran ante un tribunal formado exclusivamente por jueces profesionales. Sin embargo, se ha argumentado que aunque no actúe el jurado, la intervención por parte del

MALAN. Origens históricas dos sistemas acusatório e inquisitivo. Revista dos Tribunais, v. 842, p. 413-435, 2005.

E. VALLINES GARCÍA, ob.cit., pp. 28-36. 
juez en la actividad probatoria, implica favorecer la posición de una de las partes en contra de la otra y ello rompe la necesaria neutralidad que debe mantenerse en el debate contradictorio. Lógicamente si el proceso se define como un conflicto entre partes, como una contienda entre adversarios, cualquier intromisión supone apoyar a una parte en detrimento de su oponente. ¿Pero significa esto que se ve afectada la garantía de la imparcialidad judicial? ¿Pierde por ello el juez su condición de tercero ajeno al proceso? ¿Surgen por ello dudas razonables de que no juzgará los hechos sometido exclusivamente a la ley sin influencias indebidas?

\section{LA INTERVENCIÓN EN LA PRUEBA NO DETERMINA UNA ACTUACIÓN PARCIAL}

A la vista de cómo se ha definido el concepto de parcialidad más arriba -incidencia de elementos subjetivos ajenos a la ley y el proceso a favor de una de las partes en la decisión judicial-, no parece que pueda concluirse que una posición más activa del juez en el interrogatorio de los testigos e incluso que llamara a declarar a alguno que figura en los autos, incida en la imparcialidad. Si repasamos las diferentes definiciones de la imparcialidad, con esa actuación el juez no se convierte en parte, no abandona su posición trascedente, no denota necesariamente interés en el resultado del proceso, no expresa un estado de ánimo ni se deja llevar por emociones ajenas a la aplicación del derecho, ni por ello deja de ser ajeno a la disputa o conflicto que se dirime en el proceso penal. Además, tampoco veo cómo perjudicaría esa intervención del juez cuando completa el interrogatorio, aclara respuestas o llama a algún testigo a la fairness del proceso. Sólo una artificial compartimentación del hecho histórico en dos relatos enfrentados es lo que lleva a interpretar que la intervención del juez en el esclarecimiento de los hechos -únicos, no la versiones de los mismos que cada parte presenta-, supone perder su imparcialidad.

Por ello, a mi juicio el argumento de la imparcialidad judicial no exige relegar al tribunal a una posición de mudo espectador en el desarrollo de un proceso penal sin jurado. Es la concepción del proceso como un trasunto entre partes la que lleva a limitar los poderes del juez, pero no porque así lo exija el principio de imparcialidad. 
Una vez afirmado esto, es preciso matizar que, obviamente, si esa intervención denota un prejuicio previamente establecido a favor o en contra de una de las partes, o deja vislumbrar una anticipación del fallo, en ese caso, sin duda, podemos hablar de una quiebra de la garantía de la imparcialidad. Ahora bien, esa quiebra de la imparcialidad no se produciría tanto por la intervención en la prueba al formular alguna pregunta al testigo o al interrogar al acusado, sino por el tono, el contenido o la intensidad de esa actuación en la práctica de la prueba.

$\mathrm{Al}$ respecto es interesa citar la sentencia del Tribunal Supremo de 10 de marzo de $2016^{70}$, en la que se afirma que la imparcialidad del juez no se ve afectada cuando hace un uso razonable y moderado de las posibilidades de introducir preguntas en el interrogatorio de testigos para obtener aclaraciones de sus testimonios. Afirma el Tribunal Supremo que al considerar si el tribunal de primera instancia ha excedido sus poderes, se deben tener en cuenta los siguientes elementos: la complejidad del caso, la naturaleza y la forma de las preguntas formuladas por el juez. En esa ocasión, sin embargo, el Tribunal Supremo, concluyó que formular 78 preguntas dirigidas al acusado con el fin de establecer su culpabilidad, implicaba ir mucho más allá de la mera complementación del interrogatorio de las partes, convirtiéndose en un juez inquisidor, contraviniendo así el principio contradictorio ${ }^{71}$.

Por tanto, que el juez intervenga en la práctica de la prueba no afecta necesariamente a la imparcialidad judicial, no es incompatible con su rol de árbitro ante el enfrentamiento de dos partes en el debate contradictorio. Pero, dependiendo de cómo articule esa intervención, de la intensidad de la misma y del modo en que se exprese al desarrollarla, sí puede verse afectada la imparcialidad y la imagen de imparcialidad.

Además, que no se trata de una intervención contraria per se a la imparcialidad, queda patente en el hecho de que no sólo en el proceso penal federal de los USA admita esa intervención por parte del juez en

70 STS (Sala Penal) 922/2016, de 10 de marzo de 2016.

71 Los riesgos de esa persecución frente al acusado por parte del tribunal enjuiciador son puestos de relieve en el trabajo de F. Agnet Fayet, r. eggert poll, "Ânimo persecutório do magistrado: a quebra do dever de imparcialidade e sucessivas decisões contrárias ao direito à prova defensiva”, en este mismo volumen. 
el contra-interrogatorio de los testigos, sino que también está admitida en el proceso más acusatorio en el ámbito del derecho continental europeo, que es el proceso penal italiano. En este último, se considera que la intervención del juez en la prueba no altera el contradictorio ni, por tanto, incide necesariamente en la imparcialidad. El Codice de Procedura Penale contempla que el juez pueda formular directamente preguntas a los testigos con el fin de clarificar o completar su testimonio, pero también para explorar determinados aspectos no previamente formulados ${ }^{72}$. Tal facultad podrá ejercitarla el juez una vez que las partes hayan concluido con el contrainterrogatorio, y siempre que a las partes se les confiera la oportunidad de repreguntar al testigo después de haber respondido a las preguntas del juez. ${ }^{73}$

En el ordenamiento jurídico español, el art. 708 de la Ley de Enjuiciamiento Criminal, prevé también esa intervención del tribunal ex officio en el interrogatorio de los testigos, lo cual nunca se ha cuestionado desde la vertiente de la imparcialidad ${ }^{74}$.

Por tanto, parece bastante obvio que, si incluso en los sistemas de corte más adversarial en los que la iniciativa probatoria recae de manera casi exclusiva en las partes, se admite cierta iniciativa probatoria del tribunal, es porque ello no afecta al principio de imparcialidad. Sólo si el modo de interrogar denotara una anticipación del fallo, entonces se apreciaría esa quiebra de la imparcialidad. Y sólo si la intervención fuera excesivamente incisiva a favor de la posición de una de las partes, podría considerarse que afecta al principio de igualdad de armas.

En conclusión, que el tribunal formule preguntas a los testigos, a los peritos o a los abogados o incluso, que solicitara a las partes que aportaran alguna prueba que considera apropiada para poder esclarecer

72 Así G. ILLUMINATI, “El sistema acusatorio en Italia”, en L. Bachmaier Winter (ed.) Proceso penal y sistemas acusatorios, Madrid 2008, pp.135160 , p. 157.

73 Ibidem.

${ }^{74}$ Para los modelos procesales en Latinoamérica, vid. el trabajo de R. J. de Castilho Barilli, "A centralidade do juízo oral no Sistema Acusatório: uma visão estratégica acerca do caso penal" en este mismo volumen, en el cual el autor destaca cómo las reformas procesales en Latinoamérica se han encaminado hacia un proceso presidido por la oralidad como respuesta frente a los excesos del proceso de corte inquisitivo anterior. 
los hechos, no atenta per se contra la imparcialidad judicial. ${ }^{75} \mathrm{Si}$ un ordenamiento jurídico opta por limitar esa intervención y atribuir al juez un papel de mudo espectador, la razón no ha de encontrarse en la garantía de la imparcialidad.

\section{INTERVENCIÓN EN LA PRÁCTICA DE LA PRUEBA E IMAGEN DE IMPARCIALIDAD}

Resta por plantearse si el hecho de otorgar mayores facultades al tribunal en la iniciativa probatoria y en el desarrollo del contradictorio - no siendo incompatible con la imparcialidad- ¿puede sin embargo afectar a la imagen de imparcialidad del juez y de la justicia?

La respuesta aquí, al igual que en el punto anterior, no es sencilla: dependerá de cómo se desarrolle esa intervención. Si la actuación del juez en la búsqueda de la verdad mantiene la equidistancia y formula sus preguntas de forma neutral, la imagen de imparcialidad no sólo no tendría porqué verse perjudicada, sino que incluso, ese comportamiento podría incrementar la confianza de las partes en la justicia: mediante su intervención activa en la prueba, las partes apreciarían no sólo la profesionalidad del juez, sino también su interés en el acierto del fallo.

Pero, nuevamente, si mediante su conducta - en la prueba como en cualquier otro ámbito - el juez denota un prejuicio frente al acusado, entonces queda afectada la imparcialidad.

\section{A MODO DE CONCLUSIÓN}

En este trabajo he intentado reflejar los argumentos que mostrarían que una limitada iniciativa probatoria por parte del tribunal en el

75 En la doctrina brasileña: A. GRINOVER. A marcha do processo. Rio de Janeiro, 2000; M. ZILLI. A Iniciativa Instrutória do Juiz no Processo Penal. São Paulo, 2003. Con visión distinta: J. COUTINHO. Introdução aos princípios gerais do direito processual penal brasileiro. Revista de Estudos Criminais, São Paulo, n. 01, p. 26-51, 2001; G. PRADO. Sistema Acusatório. A conformidade constitucional das leis processuais penais. $4^{\mathrm{a}}$ ed. Rio de Janeiro, 2006; A. LOPES JR. Direito Processual Penal. 9ª ed. São Paulo, 2012. 
desarrollo del juicio oral sin jurado, no es incompatible con el principio de imparcialidad judicial. En los procesos con jurado, la intervención del juez sí puede tener una repercusión mayor en la formación de la convicción por parte del jurado y por tanto incidir en su percepción objetiva del debate contradictorio. Por ello en ese tipo de procesos penales, la intervención del juez en la práctica de la prueba debe, si no eliminarse, sí limitarse al máximo.

Dicho lo anterior, el alcance y la intensidad de la intervención del juez en la práctica de la prueba se verá modulada por el modelo de proceso que se haya adoptado en cada ordenamiento jurídico. Mientras que los sistemas acusatorios más estrictos optan por limitar o minimizar esa intervención, para así dar protagonismo a las partes en la conformación del debate contradictorio, en los sistemas de corte mixto o acusatorio menos estricto, en los que el tribunal asume un papel más central en la búsqueda de la verdad y en los que la responsabilidad del estado en el esclarecimiento de los hechos sigue desempeñando un papel central -como sería el caso del sistema alemán- ${ }^{76}$, la intervención del tribunal enjuiciador en el interrogatorio a los sujetos de prueba, tiende a ser más amplio e incisivo. Se admite que el juez adopte una posición más inquisitiva, en el sentido, de posición más activa en el juicio oral de cara a esclarecer los hechos. Pero, la intensidad de esa actuación no necesariamente tiene una correlación con la imparcialidad del tribunal: más facultades de intervención en la prueba no significa automáticamente menos imparcialidad.

Ahora bien, si la pregunta es si, al conferir mayores poderes de intervención pueden surgir más situaciones en las que el juez llegue a transgredir los límites de su función o a mostrar sus prejuicios, la respuesta es clara: a más oportunidades de intervenir también más oportunidades de que mediante esa intervención pueda verse afectada la imagen de imparcialidad. Pero, ese no es un motivo suficiente para relegar al tribunal a una posición de mudo espectador. Sería como afirmar que el sujeto que

76 Vid. el art. 244 de la Strafprozessordnung, en el que se regula la práctica de la prueba en el juicio oral: "(2) Das Gericht hat zur Erforschung der Wahrheit die Beweisaufnahme von Amts wegen auf alle Tatsachen und Beweismittel zu erstrecken, die für die Entscheidung von Bedeutung sind." 
más habla más se equivoca, y por ello condenar al silencio a todo sujeto, en este caso, a todo juez.

A partir de ahí, y clarificado que el principio de imparcialidad no es un argumento determinante para eliminar cualquier intervención del juez en la práctica de la prueba en el juicio oral, esa intervención vendrá determinada por el tipo de modelo de proceso adoptado. Sin duda, un proceso puramente adversarial, en el que las pruebas se aportan para defender una concreta posición de parte y no son concebidas como pruebas del caso en general, la intervención del juez en la práctica de la prueba se percibirá como a favor o en contra de esa parte.

Dicho esto, queda en manos del legislador configurar el proceso penal, otorgando al juez más o menos poderes, al margen de que ambos modelos se ajustan a la garantía de la imparcialidad. En esa elección incidirán muchos factores de tipo cultural, legal, político, histórico, económico, etc. y el fin que se considere ha de desempeñar el proceso penal en esa sociedad - más próximo al fin de resolución de conflictos, de control social o de instrumento para implementar una determinada política criminal. Pero ese es otro debate, que si bien está estrechamente vinculado al tema que aquí he abordado, obviamente excede del objetivo que me he propuesto aquí.

\section{Referencias Bibliográficas}

ABEL LLUCH, X., Iniciativa probatoria de oficio en el proceso civil, Barcelona 2005.

ARIAS DOMÍNGUEZ, A., La abstención y la recusación de jueces y magistrados, Madrid 1999.

BADARÓ, G. Ônus da prova no processo penal. São Paulo, 2003.

BADARÓ, G. Juiz Natural no Processo Penal. São Paulo, 2014.

BACHMAIER WINTER, L. (ed.), Proceso penal y sistemas acusatorios, Madrid 2008.

BACHMAIER WINTER, L. Imparcialidad Judicial y Libertad de Expresión de Jueces y Magistrados. Las recusaciones de Magistrados del Tribunal Constitucional, Cizur Menor 2008.

BACHOF, O., Grundgesetz und Richtermacht, Tübingen 1959. 
BAILEY, S.H., CHING, J., GUNN, M., y ORMEROD, D., Smith, Bailey \& Gunn on the Modern English System, London 2002.

BAUR, F., Justizaufsicht und richterliche Unabhängigkeit, Tübingen 1954.

BETTERMANN, K.A., "Vom Sinn und von den Grenzen der richterlichen Unabhängigkeit”, en Die Unabhängigkeit des Richters, Köln 1969, p. 53.

CALAMANDREI, P., Processo e democrazia, Padova 1954.

CALAMANDREI, P., Proceso y democracia, Buenos Aires 1960.

CAPPELLETTI, M., "Fundamental Guarantees of the parties in the civil proceedings (General Report) Cappelletti, en Fundamental Guarantes (con D. Tallon), Milano 1972.

CARNELUTTI, F., Diritto e processo. Trattato del processo civile, Napoli 1958.

CARNELUTTI, F., Sistema di diritto processsuale civile, t. IV, Padova 1936.

COTTA, S., "L'istituzione giudiziaria tra diritto e politica”, Riv. Diritto Civ., 1984I, p. 430 .

COUTINHO, J. Introdução aos princípios gerais do direito processual penal brasileiro. Revista de Estudos Criminais, São Paulo, n. 01, p. 26-51, 2001.

COUTINHO, J. O papel do novo juiz no processo penal. In: COUTINHO, Jacinto Miranda (coord.). Crítica à Teoria Geral do Direito Processual Penal. Rio de Janeiro, 2001.

DAMASKA, M., The faces of justice and state authority. A comparative approach to legal process, New Haven 1986.

DAMASKA, M., Evidence Law Adrift, New Haven 1997.

DAMASKA, M., "Truth in Adjudication”, (1998) 49 Hasting Law Journal, p. 289.

DÍAZ CABIALE, J.A., Principios de aportación de parte y acusatorio: la imparcialidad del juez, Granada, 1996.

ESPARZA LEIBAR, I., El principio del proceso debido, Barcelona 1995.

FARANDA, C., La capacità del giudice, Milano 1958.

FAZZALARI, E., “La imparzialità del giudice”, Riv. Dir. Proc., 1972.

FERRER BELTRÁN, J., Prueba y verdad en el Derecho, Barcelona 2005.

FERRER BELTRÁN, J., "Los poderes probatorios del juez y el modelo de proceso", Cuadernos Electrónicos de Filosofía del Derecho, núm. 36 (2017), pp. 88-108. 
GIMENO SENDRA, V., "Poder judicial, potestad jurisdiccional y legitimación de la actividad judicial”, Rev. Dcho. Proc., 1978, p. 336.

GOLDSCHMIDT, W., "La imparcialidad como principio básico del proceso”, Rev. Dcho. Proc., 1950-2, pp. 186-187.

GRINOVER, A. A marcha do processo. Rio de Janeiro, 2000.

GUZMÁN, N., La verdad en el proceso penal. Una contribución a la epistemología jurídica, Buenos Aires 2006.

HOBGOOD, H.H., "When should a trial judge intervene to question a witness?", 3 Campbell Law Rev. (1981), pp. 69-76.

ILLUMINATI, G., "El sistema acusatorio en Italia”, en L. Bachmaier Winter (ed.) Proceso penal y sistemas acusatorios, Madrid 2008, pp.135-160.

JIMÉNEZ ASENSIO, R., Imparcialidad judicial y derecho al juez imparcial, Cizur Menor, 2002.

KUIJER, M., The Blindfold of Lady Justice. Judicial Independence and Impartiality in Light of the Requirements of Article 6 ECHR, Leiden 2004.

LANGER, M. "In the Beginning was Fortescue: On the Intellectual Origins of the Adversarial and Inquisitorial Systems and Common and Civil Law in Comparative Criminal Procedure" en B. Ackerman, K. Ambos y H. Sikiric (eds.), Visions of Justice, Liber Amicorum Mirjan Damaska, Berlin 2016, pp. 273-299.

LOPES JR., A. Direito Processual Penal. 9ª ed. São Paulo, 2012.

LÓPEZ AGUILAR, J.F., La justicia y sus problemas en la Constitución: justicia, jueces y fiscales en el Estado Social y Democrático de Derecho, Madrid 1996.

MAYA, A. M. Imparcialidade e Processo Penal da Prevenção: da competência ao juiz das garantias. Rio de Janeiro, 2011.

MONTERO AROCA, J., Independencia y responsabilidad del juez, Madrid 1990.

MONTERO, J., Sobre la imparcialidad del juez y la incompatibilidad de funciones procesales, Valencia 1999.

PICÓ i JUNOY, J., "Reflexiones en torno a la cuestionada iniciativa probatoria del juzgador penal”, Revista Justicia 1-1996.

PICÓ i JUNOY, J., El juez y la prueba. Estudio de la errónea recepción del brocardo iudex iudicare debet secundum allegata et probata non secundum conscientiam y su repercusión actual, Barcelona 2007. 
PRADO, G. Sistema Acusatório. A conformidade constitucional das leis processuais penais. $4^{\mathrm{a}}$ ed. Rio de Janeiro, 2006.

RAWLS, J., A Theory of Justice, Oxford 1999.

REID, K., A practitioner's Guide to the European Convention on Human Rights, London 2008.

REQUEJO PAGÉS, J. L., Jurisdicción e independencia judicial, Madrid 1989.

RIEDEL, J., Das Postulat der Unparteilichkeit des Richters, Berlin 1980.

SAAD, M.; MALAN, D. Origens históricas dos sistemas acusatório e inquisitivo. Revista dos Tribunais, v. 842, p. 413-435, 2005.

SERRA CRISTÓBAL, R., La libertad ideológica del juez, Valencia 2004.

SIMON, D., La independencia del Juez (trad. de C. Ximénez-Carrillo), Barcelona 1985.

SLAPPER G./ KELLY, D., Sourcebook on the English Legal System, London 2001.

STEMMLER, C., Befangenheit im Richteramt. Eine systematische Darstellung der Ausschließungs- und Ablehnungsgründe unter Berücksichtigung des gesetzlichen Richters als materielles Prinzip, Tübingen 1975.

TARUFFO, M., La prova dei fatti giuridici: nozioni generali, Milano1992.

VALLDECABRES ORTIZ I., La imparcialidad del Juez y medios de comunicación, Valencia 2004.

VALLINES GARCÍA, E., Instrumentos para garantizar la imparcialidad e independencia de los jurados, Cizur Menor, 2008.

VASCONCELLOS, V. Sistemas Processuais Penais: as contribuições das visões histórica e de direito comparado para o desvelamento da essência acusatória. Revista de Estudos Criminais, v. 58, p. 127-152, 2015.

VASCONCELLOS, V. O ,Sistema Acusatório‘ do Processo Penal Brasileiro: Apontamentos Acerca do Conteúdo da Acusatoriedade a partir de Decisões do Supremo Tribunal Federal. Direito, Estado e Sociedade, n. 47, p. 181-204, jul./dez. 2015. http://dx.doi.org/10.17808/des.47.604

VIVES ANTÓN, T.S., Comentarios a la Ley de medidas urgentes de reforma procesal. La reforma del proceso penal, Valencia 1992.

WASSERMANN, R., Die richterliche Gewalt. Macht und Verantwortung des Richters in der modernen Gesellschaft, Heidelberg 1985.

ZILLI, M. A Iniciativa Instrutória do Juiz no Processo Penal. São Paulo, 2003. 


\section{Informações adicionais e declarações do autor (integridade científica)}

Declaração de conflito de interesses (conflict of interest declaration): a autora confirma que não há conflitos de interesse na realização das pesquisas expostas e na redação deste editorial.

Declaração de autoria (declaration of authorship): todas e somente as pessoas que atendem os requisitos de autoria deste editorial estão listadas como autores; todos os coautores se responsabilizam integralmente por este trabalho em sua totalidade.

Declaração de ineditismo e originalidade (declaration of originality): a autora assegura que o texto aqui publicado não foi divulgado anteriormente em outro meio e que futura republicação somente se realizará com a indicação expressa da referência desta publicação original; também atesta que não há plágio de terceiros ou autoplágio.

\section{COMO CITAR ESTE EDITORIAL:}

BACHMAIER WINTER, Lorena. Editorial dossier "Sistemas procesales penales e imparcialidad del juez": Imparcialidad y prueba en el proceso penal - reflexiones sobre la iniciativa probatoria del juez. Revista Brasileira de Direito Processual Penal, Porto Alegre, vol. 4, n. 2, p. 501-532, mai./ago. 2018.

https://doi.org/10.22197/rbdpp.v4i2.169

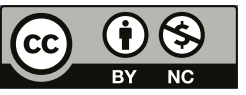

Esta obra está licenciada com uma Licença Creative Commons Atribuição-NãoComercial 4.0 Internacional. 